\title{
Bacteraemia in patients receiving human cadaveric renal transplants
}

\author{
D. A. LEIGH \\ From the Department of Bacteriology, The Wright-Fleming Institute, St Mary's Hospital, London
}

SYNOPSIS During a two-year period (1966 to 1968) 70 patients were admitted to the Renal Transplantation Unit at St Mary's Hospital and 22 (31\%) developed bacteraemia.

Eighteen of the 25 episodes of bacteraemia occurred after transplantation and seven before. The typical clinical syndrome was uncommon and was only seen in $32 \%$ of cases. The presence of shock was not recognizable in the majority of patients probably because they were already receiving steroid therapy.

The commonest infecting organism was Ps. aeruginosa (nine cases) and Gram-negative bacilli accounted for $72 \%$ of the bacteraemias. Staph. aureus was isolated in five patients.

A likely source of the infecting organism was found in $80 \%$ of cases and the commonest source was the urinary tract.

Serious complications were present in 13 episodes of bacteraemia, and these were peritonitis before transplantation, necrosis of the donor ureter, and severe rejection or polar infarction in the donor kidney after transplantation.

Bacteraemia due to Gram-negative bacilli was associated with complications in $61 \%$ of cases. $P s$. aeruginosa was almost invariably isolated from complicated cases though Esch. coli was only seen in simple cases.

Antibiotic treatment was successful in $64 \%$ of cases but the cure rate was higher $(86 \%)$ before transplantation than after transplantation $(55 \%)$. Although the presence of complications did not affect the cure rate in Gram-positive bacteraemia, the cure rate in complicated Gram-negative bacteraemias was poor and associated with a mortality of over $70 \%$.

Patients receiving human cadaveric renal transplants are susceptible to all kinds of bacterial infection including bacteraemia, and the results of antibiotic treatment are dependent on both the nature of the infecting organism and the presence of serious underlying complications.

The incidence of bacteraemia both due to Grampositive and Gram-negative bacteria has increased over the last 15 years (Finland, Jones, and Barnes, 1959; Watt and Okubadejo, 1967; Murdoch, Spiers, and Pullen, 1968) and there has been a change in the relative incidence of infecting organisms (Finland et al, 1959).

The great majority of patients with bacteraemia have severe underlying disease or have undergone surgical procedures, and high incidences of bacteraemia have been described following urinary tract surgery or instrumentation, in severe skin infections and burns, and in patients with impaired body defence mechanisms as seen with malignancy, blood

'Present address: Wycombe \& Amersham General Hospitals. Received for publication 20 August 1970. dyscrasias, and patients on immunosuppressive or steroid therapy.

Bacteraemia may be associated with a state of 'shock' and this has been reported as occurring in up to $52 \%$ of Gram-negative bacteraemias and up to $25 \%$ of Gram-positive bacteraemias (McCabe and Jackson, 1962; Weil, Shubin, and Biddle, 1964; Melnick and Litvak, 1966; Murdoch et al, 1968). Bacteraemic shock has been reported as the second commonest cause of death in hospital patients (MacLean, 1962).

Patients undergoing renal transplantation receive large doses of steroids and are highly susceptible to many kinds of bacterial infection. It would be expected that a high incidence of bacteraemia would also be found in this group of patients. Many studies 
describe the incidence of bacterial infection following renal transplantation but few report the incidence of bacteraemia. Kelly, Lillehei, Aust, Varco, Leonard, Griffin, Markland, Herdman, Vernier, Michael, and Levitt (1967), however, report an incidence of $42 \%$ in patients receiving cadaveric renal transplants and MacLean, Dossetor, Gault, Oliver, Inglis, and MacKinnon (1965) found that septicaemia was a direct cause of death in four out of eight patients who died following renal transplantation.

\section{Patients and Methods}

Patients admitted to the Renal Unit were in the terminal stages of chronic renal failure with a creatinine clearance of less than $2 \mathrm{ml}$ per minute. The patients were maintained by peritoneal dialysis until a cadaver kidney became available. Details of the dialysis procedure have already been fully described (Cohen and Percival, 1968; Leigh, 1969).

The patients were examined bacteriologically according to a strict daily routine. Specimens of peritoneal dialysis effluent fluid before transplantation and specimens of urine after transplantation were examined daily. Swabs from the nose, throat, and vagina and faeces were examined once a week, and a swab from the skin around the dialysis catheter was examined twice a week. Blood cultures were routinely taken every day for four days following transplantation and at any time when clinically indicated.

All organisms causing infection and those of epidemiological importance were accurately identified by routine laboratory procedures, including serotyping, phage typing, and pyocine typing. The antibiotic sensitivities of infecting organisms isolated from cases of bacteraemia were initially determined using the impregnated disc technique and later by a tube dilution method.

Antibiotic treatment was always given systemically, in many cases by continuous intravenous infusion, and the dose was regulated by estimation of the blood levels. In some cases two antibiotics were given and in the majority of these a synergistic effect against the infecting organism had been proved by laboratory tests.

After transplantation all patients were given large doses of immunosuppressive therapy (Imuran and prednisone). In the first year of the study only, small doses were also given before transplantation.

Because of the difficulties of clinical diagnosis, bacteraemia was only judged to be present when bacteria were isolated from a blood culture. A cure was defined as a clinical response to treatment associated with eradication of bacteria from the blood stream. In many cases, however, the causative organism persisted in the primary focus of infection.

\section{Results}

Between October 1966 and October 196870 patients were admitted to the Renal Transplantation Unit and 45 of these subsequently received cadaver kidneys. Twenty-two (31\%) patients developed 25 episodes of bacteraemia, three patients having two $\vec{\circ}$ episodes. Seven episodes of bacteraemia occurred before transplantation and 18 after transplantation.

The incidence of bacteraemia before transplantation was $10 \%$ and after transplantation $40 \%$. Gramnegative bacteraemia was almost three times as common as Gram-positive bacteraemia both before and after transplantation (Table I).

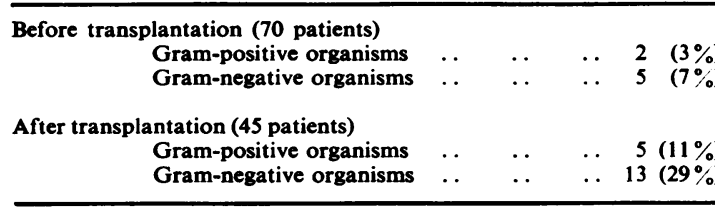

Table I Incidence of bacteraemia before and after renal transplantation

CLINICAL PRESENTATION OF BACTERAEMIA Only eight $(32 \%)$ of the 25 patients presented the typical clinical syndrome of bacteraemia and five of these occurred after transplantation. Fourteen $(56 \%)$ ? cases of bacteraemia occurred in severely ill patients and frequently the only sign was hypotension. Many of these patients were febrile due to associated 0 infections and the shock syndrome was not recog- 2 nizable, probably because these patients were already 욱 receiving steroid therapy. Ten of these 14 episodes $\rightarrow$ of bacteraemia occurred after transplantation. The remaining three cases were completely asympto- N matic and occurred after transplantation.

INFECTING ORGANISMS

The distribution of infecting organisms is shown in Table II. Eighteen $(72 \%)$ of the 25 cases of bacter- 6 aemia were due to Gram-negative bacteria, and the $\frac{}{\Phi}$ commonest organism was Pseudomonas aeruginosa $\stackrel{?}{+}$ which occurred in nine cases. The remaining seven $\underline{T}$ $(28 \%)$ cases were due to Gram-positive cocci and $\stackrel{\vec{D}}{\circ}$ Staph. aureus was isolated in five episodes of bacter- $\stackrel{\mathcal{D}}{\stackrel{\perp}{\circ}}$ aemia. The proportion of Gram-negative to Gram- $\mathbb{\otimes}$ positive bacteraemia was the same before and after transplantation. 


\begin{tabular}{llll}
\hline Organism & $\begin{array}{l}\text { Before } \\
\text { Transplantation }\end{array}$ & $\begin{array}{l}\text { After } \\
\text { Transplantation }\end{array}$ & Total \\
\hline Gram-negative & & 7 & 9 \\
$\quad \begin{array}{l}\text { Ps.aeruginosa } \\
\text { Esch.coli }\end{array}$ & 2 & 4 & 6 \\
$\quad \begin{array}{l}\text { Klebsiella spp } \\
\text { Bacteroides spp }\end{array}$ & 1 & 1 & 1 \\
Total & $\mathbf{5}$ & 1 & 18 \\
$\begin{array}{lll}\text { Gram-positive } \\
\quad \text { Staph. aureus }\end{array}$ & 1 & 4 & 5 \\
$\quad$ Strept.pneumoniae & - & 1 & 1 \\
$\quad$ Strept. viridans & 1 & -5 & 7 \\
Total & 2 & 18 & 25 \\
Overall total & 7 & 5 & \\
\hline
\end{tabular}

Table II Infecting organisms in 25 bacteraemic patients

SUORCE OF THE INFECTING ORGANISM AND PERESENCE OF COMPLICATIONS

It was possible to find a likely source for the infecting organism in 20 of the 25 cases of bacteraemia. The most common source was the urinary tract (11 cases) but other sources were the peritoneum (3 cases), the lung ( 2 cases), and a postoperative wound ( 2 cases). In the remaining two cases a similar organism was isolated from the faeces.

Thirteen episodes of bacteraemia were considered to be 'complicated', ie, a severe underlying abnormality or infection was present. Necrosis of the donor ureter and peritonitis were each present in four cases. In three cases severe rejection of the donor kidney had occurred causing a deterioration in renal function, and in the remaining two cases an infection of the upper pole of the grafted kidney was found at necropsy and the infecting organism was isolated from this area.

The association of complications with the nature of the infecting organism is shown in Table III. Gram-negative bacilli were associated with complications in $61 \%$ of cases and $P$ s. aeruginosa was almost invariably isolated from cases with severe

\begin{tabular}{lcl}
\hline Organism & Total & $\begin{array}{l}\text { No. Associated } \\
\text { with Abnormality }\end{array}$ \\
\hline $\begin{array}{l}\text { Gram-negative } \\
\text { Ps. aeruginosa }\end{array}$ & 9 & $8(89 \%)$ \\
$\quad$ Esch.coli & 6 & 0 \\
Klebsiella spp & 2 & 2 \\
Bacteroides spp & 1 & 1 \\
Total & 18 & $11(61 \%)$ \\
Gram-positive & & \\
$\quad$ Staph. aureus & 5 & $2(40 \%)$ \\
$\quad$ Strept.pneumoniae & 1 & 0 \\
$\quad$ Strept. viridans & 1 & 0 \\
Total & 7 & $2(29 \%)$ \\
\hline
\end{tabular}

Table III Association of type of infecting organism with the presence of an underlying abnormality complications. In contrast Esch. coli was only seen in 'simple' cases where no known complications were present. Only two $(29 \%)$ of the seven bacteraemias due to Gram-positive cocci were associated with complications.

\section{Results of Treatment}

The results of treatment are shown in Table IV. The overall cure rate was $64 \%$ but it was higher before transplantation $(86 \%)$ than after transplantation $(55 \%)$. Although there was little difference in the cure rate with Gram-positive organisms before and after transplantation, with Gram-negative bacilli the cure rate before transplantation was almost twice as high as that after transplantation. This was due mainly to the poor cure rate achieved in bacteraemias due to $P$ s. aeruginosa, where complications were common.

The relationship of complications to the results of treatment and death is shown in Table V. The cure rate in Gram-positive bacteraemia was similar whether complications were present or not. In Gram-negative bacteraemias, although all simple infections were cured, the cure rate with complicated infections was poor, only three $(27 \%)$ of 11 bacter-

\begin{tabular}{|c|c|c|c|c|c|c|}
\hline \multirow[t]{2}{*}{ Organism } & \multicolumn{2}{|c|}{$\begin{array}{l}\text { Before } \\
\text { Trans- } \\
\text { plantation }\end{array}$} & \multicolumn{2}{|c|}{$\begin{array}{l}\text { After } \\
\text { Trans- } \\
\text { plantation }\end{array}$} & \multicolumn{2}{|c|}{ Total } \\
\hline & No. & Cure & No. & Cure & No. & Cure \\
\hline $\begin{array}{l}\text { Gram-negative } \\
\text { Ps. aeruginosa } \\
\text { Esch. coli } \\
\text { Klebsiella } \text { spp } \\
\text { Bacteroides spp } \\
\text { Total }\end{array}$ & $\begin{array}{l}2 \\
2 \\
1 \\
5\end{array}$ & $\begin{array}{l}1(50 \%) \\
2 \\
\frac{1}{4(80 \%)}\end{array}$ & $\begin{array}{r}7 \\
4 \\
1 \\
1 \\
13\end{array}$ & $\begin{array}{l}1(14 \%) \\
4 \\
0 \\
1 \\
6(46 \%)\end{array}$ & $\begin{array}{r}9 \\
6 \\
2 \\
1 \\
18\end{array}$ & $\begin{array}{l}2(22 \%) \\
6 \\
1(50 \%) \\
1 \\
10(55 \%)\end{array}$ \\
\hline $\begin{array}{l}\text { Gram-positive } \\
\text { Staph. aureus } \\
\text { Strept. pneumoniae } \\
\text { Strept. viridans } \\
\text { Total }\end{array}$ & $\frac{1}{1}$ & $\begin{array}{l}\frac{1}{1} \\
2(100 \%)\end{array}$ & $\begin{array}{r}4 \\
1 \\
5\end{array}$ & $\begin{array}{l}3(75 \%) \\
\frac{1}{4}(80 \%)\end{array}$ & $\begin{array}{l}5 \\
1 \\
1 \\
7\end{array}$ & $\begin{array}{l}4(80 \%) \\
1 \\
1 \\
6(86 \%)\end{array}$ \\
\hline Overall total & 7 & $6(86 \%)$ & 18 & $10(55 \%)$ & 25 & $16(64 \%)$ \\
\hline
\end{tabular}

Table IV Results of treatment

\begin{tabular}{lcll}
\hline Organism & Total & Cure & Deaths \\
\hline $\begin{array}{l}\text { Gram-negative } \\
\text { Simple }\end{array}$ & 7 & $7(100 \%)$ & 0 \\
Complicated & 11 & $3(27 \%)$ & $8(73 \%)$ \\
$\begin{array}{l}\text { Gram-positive } \\
\text { Simple }\end{array}$ & 5 & $4(80 \%)$ & 1 \\
Complicated & 2 & $2(100 \%)$ & 0 \\
\hline
\end{tabular}

Table V Relationship of complications to the result of treatment and death 
aemias responding to treatment. Death was uncommon in Gram-positive bacteraemia irrespective of complications whereas in complicated Gram-negative bacteraemia all patients died although only eight $(73 \%)$ of the 11 patients died as a result of the bacteraemia. The remaining three patients died because of persistence of the organism in the primary focus of infection.

\section{Discussion}

The clinical importance of bacteraemia has increased over the last two decades, and Finland et al (1959) have shown the change in the ratio between Gram-negative and Gram-positive infections. Later writers have confirmed these initial findings (McCabe and Jackson, 1962; Watt and Okubadejo, 1967; Murdoch et al, 1969).

Bacteraemia commonly occurs in patients with severe underlying abnormalities or disease, especially those receiving steroid, immunosuppressive, or cytotoxic therapy. Patients receiving organ transplants might be expected to be at great risk, and Kelly et al (1967) have reported that bacteraemia occurred in $39 \%$ of patients receiving renal transplants from live donors and in $42 \%$ of those receiving cadaveric kidneys. Hill, Dahrling, Starzl, and Rifkind (1967) found that infection was a direct cause of death iu $86 \%$ of patients who died following renal transplantation but the incidence of bacteraemia was not given. MacLean et al (1965) earlier had reported that septicaemia was a direct cause of death in four of eight renal transplant patients who died. These patients receive high doses of immunosuppressive therapy and steroids and it has been reported that the administration of steroids is an important causative factor in the development of infections (Hill et al, 1967).

In this study of 70 patients in a renal transplantation unit, 22 patients developed episodes of bacteraemia. Bacteraemia due to both Gram-positive and Gram-negative organisms was more common after transplantation than before and this is undoubtedly related to immunosuppressive therapy and the greater incidence of serious abnormalities following transplantation.

The most common infecting organism was $P$ s. aeruginosa, and it was almost invariably isolated from bacteraemic patients with underlying abnormalities. In this study seven of the eight patients with complicated Ps. aeruginosa bacteraemia died. Esch. coli, probably the commonest infecting organism in all cases of bacteraemia, was isolated in six cases but none of these was associated with abnormalities and usually occurred many months after transplantation. Although this organism was not associated with severe renal disease, as the renal function of the graft was usually good, urinary tract infection, however, was frequently present and was the source of the bacteraemia.

Staph. aureus was seen in five cases and was usually secondary to minor staphylococcal infections $\overrightarrow{\mathbb{D}}$ such as postoperative wound infections elsewhere. $\stackrel{2}{2}$

The complications found were in general those कs related to dialysis, such as peritonitis, and to renal $\overrightarrow{0}$ transplantation, such as necrosis of the donor ureter $\vec{\overrightarrow{ }}$ and severe rejection of the kidney. In two cases $\vec{\omega}$ the upper pole of the donor kidney had become infected following failure to find a small accessory artery and this area had subsequently become infected.

In a group of patients where a strict daily bacter- if iological survey is carried out the infecting organism of in patients with bacteraemia can often be predicted. A likely source of the infecting bacteria was found $\vec{z}$ in $80 \%$ of the cases of bacteraemia and in over $50 \%$ 일 this was the urinary tract.

The success of antibiotic therapy in patients with $\vec{v}$ bacteraemia depends on prescribing an effective :bactericidal antibiotic at a high concentration as early as possible in the course of the infection. In this study it was usually possible to predict the causative organism and the accessibility of the primary focus of infection to the antibiotic and to prescribe the $\stackrel{\varnothing}{\perp}$ most appropriate antibiotic. Treatment, however, $\overrightarrow{\vec{P}}$ was always controlled by accurate assessment of the sensitivity of the organism to the prescribed anti- $\vec{T}$ biotic and the determination of blood levels. Where two antibiotics were given synergistic activity was always looked for. The initial treatment was usually? with either gentamicin $(40-80 \mathrm{mg}$ intramuscularly every eight hours), carbenicillin (intravenous infusion of $15-20 \mathrm{~g} /$ day or intramuscularly $2 \mathrm{~g}$ six hourly), or a combination of the two for Gram-negative bacilli and with cephaloridine or cloxacillin for Gram-음 positive cocci. The results of treatment were found $D$ to depend first on the presence of serious underlying abnormalities and second on the infecting organism. N In simple infections the cure rate in both Gramnegative and Gram-positive bacteraemias was very $\stackrel{N}{0}$ high but in complicated infections the cure rate with $\underset{\omega}{N}$ Gram-negative bacilli was poor although a good cure rate was seen with Gram-positive organisms. Thise poor cure rate was due mainly to the high failure $\Phi$ rate in bacteraemia due to Ps. aeruginosa (Table IV).

In this study the clinical presentation of bacteraemia was only typical in $32 \%$ of cases, and shock as defined by Weil and Shubin (1967) was rarely@ present. The diagnosis of bacteraemia, therefore, $\stackrel{\odot}{\varrho}$ depends on accurate clinical observation and knowledge of the group of patients at greater risk. 
Patients undergoing renal transplantation and receiving steroid and immunosuppressive therapy are a special group, and the incidence of bacteraemia is high. The results of treatment, however, can be good providing antibiotic therapy is instigated early in the course of the infection.

I should like to thank Miss C. Whittaker and the staff of the Bacteriology Department for their help with the laboratory examination of specimens, and Professor W. S. Peart for allowing me to carry out studies on his patients in the Renal Unit.

\section{References}

Cohen, S. L., and Percival, A. (1968). Prolonged peritoneal dialysis in patients awaiting renal transplantation. Brit. med. J., 1, 409-413.

Finland, M., Jones, W. F., Jr., and Barnes, M. W. (1959). Occurrence of serious bacterial infections since introduction of antibacteria agents. J. Amer. med. Ass., 170, 2188-2197.

Hill, R. B., Dahrling, B. E., Starzl, T. E., and Rifkind, D. (1967). Death after transplantation-An analysis of sixty cases. Amer. J. Med., 42. 327-334.
Kelly, W. D., Lillehei, R. C., Aust, J. B., Varco, R. L., Leonard, A. S., Griffin, W. O., Markland, C., Herdman, R. C., Vernier, R. L., Michael, A. F., and Levitt, J. (1967). Kidney transplantation: experiences at the University of Minnesota hospitals. Surgery, 62, 704-720.

Leigh, D. A. (1969). Peritoneal infections in patients on long-term peritoneal dialysis before and after human cadaveric renal transplantation. J. clin. Path., 22, 539-544.

McCabe, W. R., and Jackson, G. G. (1962). Gram-negative bacteremia. Arch. intern. Med., 110, 847-855.

MacLean, L. D. (1962). Shock due to sepsis. A summary of current concepts of pathogenesis and treatment. J. Trauma, 2, 412-423.

MacLean, L. D., Dossetor, J. B., Gault, M. H., Oliver, J. A., Inglis, F. G., and MacKinnon, K. J. (1965). Renal transplantation using cadaver donors. Arch. Surgery, 91, 288-306.

Melnick, I., and Litvak, A. S. (1966). Gram-negative bacteremia: an evaluation of 59 cases during 1963. J. Urol. (Baltimore), 96, 257-262.

Murdoch, J. C. McC., Spiers, C. F., and Pullen, H. (1968). The bacteraemic shock syndrome. Brit. J. hosp. Med., 1, 346-353.

Watt, P. J., and Okubadejo, O. A. (1967). Changes in incidence and aetiology of bacteraemia arising in hospital practice. Brit. med.J., 1, 210-211.

Weil, M. H., and Shubin, H. (1967). Diagnosis and Treatment of Shock, p. 1. Williams and Wilkins, Baltimore.

Weil, M. H., Shubin, H., and Biddle, M. (1964). Shock caused by gram-negative microorganisms: analysis of 169 cases. Ann. intern. Med., 60, 384-400. 